\title{
Molecular Nanobiotechnological approaches for the detection and therapy of prion related diseases.
}

\author{
PK Praseetha ${ }^{1 *}$, Anand S Thampy ${ }^{1}, \mathrm{P}$ Venugopalan ${ }^{1}$, Murthy S Chavali $^{1}$ \\ ${ }^{1}$ Department of Nanotechnology, Noorul Islam Centre for Higher Education, Kumaracoil, Kanyakumari District, Tamil Nadu, India. \\ * Corresponding author: E. Mail. crkpkp@gmail.com(Praseetha P.K) Tel/fax.+919486855091.
}

\begin{abstract}
Prion diseases are associated with the accumulation in the brain of an abnormal, protease resistant isoform of a host encoded glycoprotein known as prion protein (PrP). Nanotechnology in combination with biotechniques promises a broad spectrum of highly innovative approaches for overcoming the challenges posed by the prions. Recent advances in molecular nanobiotechnology have brought in the potential of molecular targeting in diagnosis and therapies of various diseases. Their high binding sensitivity and specificity added by their small size have favored the identification by in vitro protocols. Molecular targeting has initiated exciting technologies based on conjugation of biomolecules to nanoparticles. This review article is an extensive study of various research oriented nanobiotechnological protocols for rapid identification and cure for prion diseases both at in vivo and in vitro options.
\end{abstract}

Keywords: Prion, Nanobiotechnology, Detection, Therapy, Drug Delivery.

Citation: PK Praseetha, et al. Molecular Nanobiotechnological approaches for the detection and therapy of prion related diseases. Nano Biomed. Eng. 2012, 4(2), 50-57. DOI: 10.5101/nbe.v4i2.p50-57.

\section{Introduction}

Prion diseases are neurodegenerative diseases with a fatal outcome for the host. Therapies other than palliation have not promised cent percent solutions so far and hence the disease is responsible for tragic episodes for centuries. Recent reports indicate that there is a lot to be learnt about the mechanisms of prion transmission and the complex patterns of infectivity. The causative agent is reported to be PrPc- a normal protein found in brain and other organs which are converted into a misfolded, pathological form designated as PrPsc by some autocatalytic process. It is also accompanied by an insoluble form of PrP which is resistant to protease digestion [1]. Though the disease is rare in humans, research interests in the field is intense because of their unique transmissible property with a post translationally modified host protein [2]. PrPc- the normal form of protein encoded is attached to the outer surface of plasma membrane with a glycosylphosphatidyl inositol anchor and is susceptible to proteinase K. But the pathological form PrPsc is largely resistant to PK digestion [3]. Another remarkable feature of prions is the existence of many prion strains and can be propagated indefinitely. The transmission of disease from one species to another is less efficient than transmission within the same species. B lymphocytes are largely responsible for the spread and neuro invasions [4].

The NMR structure of PrP contains three $\alpha$-helices and a two stranded antiparallel $\beta$-sheet. The first turn of the second helix and the last turn of the third helix are linked by the single disulphide bond in the protein. The twisted V-shaped arrangement of these two longest helices forms the scaffold onto which the short $\beta$-sheet and the first helix are anchored [5]. The normal PrPc protein is converted to PrPsc by refolding of the $\alpha$-helical and coil to a $\beta$-sheet along with changes in the physicochemical properties of PrP. Sequence homology exists between the C-terminal domain of murine Prp with the catalytic domains of monomeric bacterial peptidases and with the catalytic subunits of eukaryotic signal peptidases [6].

The structural features of PrP are determined by NMR and Mass Spectrometric studies. Translation of PrP- mRNA produces 254 amino acids, the first two of which function as signal peptide for translation of the polypeptide chain into Endoplasmic reticulum (Fig. 1). After cleavage of another C-terminal peptide, the molecule acquires a glycosyl- phosphatidyl -inositol 


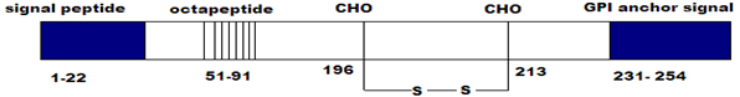

Fig. 1 Schematic diagram of a PrP protein

anchor. The polypeptide undergoes posttranslational modifications to add up $2 \mathrm{~N}$-linked carbohydrate chains. A disulphide bond stabilizes the conformation of protein. After cleavage of the $\mathrm{N}$ and C-terminal signal peptides, the mature human protein consists of 209 amino acids [7].

A key molecular event in prion diseases is the conversion of the prion protein from its normal cellular form (PrPc) to the disease form (PrPsc) (Fig.2). The transition involves a major conformational change, resulting amorphous protein aggregates and fibrillar amyloid deposits with an increased $\beta$-sheet structure [8].

The features of PrPc can be distinguished from PrPsc by the following salient features. The infectivity of PrPsc is the major factor as the PrPc is the benign form. The secondary structure of $\mathrm{PrPc}$ in composed mainly of $\alpha$-helical sheets whereas the PrPsc are constituted by $\beta$ sheets. The half life of the molecules also varies with 2-6 hours for PrPc which exceeds to 16-24 hours in PrPsc. The resistance to Proteinase K by the PrPsc molecules is an identification criterion. PrPsc molecules are insoluble in detergents after ultracentrifugation while the PrPc molecules are soluble [9].

Transgenic studies conducted on the same concluded that PrPsc acts as a template upon which PrPc is refolded into a nascent PrPsc molecule with interactions of other proteins. More than 20 mutations of the PrP gene are now known to cause the inherited human prion diseases and significant genetic linkage has been established for five of them [10].

\section{Methodologies for the detection of prions}

\section{Optical based methods}

Optical sensing methodologies have been developed to detect the changes of proteins when bound to small molecules. Surface Plasmon resonance and planar wave guide are used for the same. For this, the target protein is immobilized onto a solid surface by covalent or noncovalent interactions. Binding of molecules change the refractive index and is sensed by optical detection. SPR determines the kinetic parameters and equilibrium constants of binding [11].

Optical trapping is another important kind of diagnostic tool for prions. Amyloid fibrils are formed during the

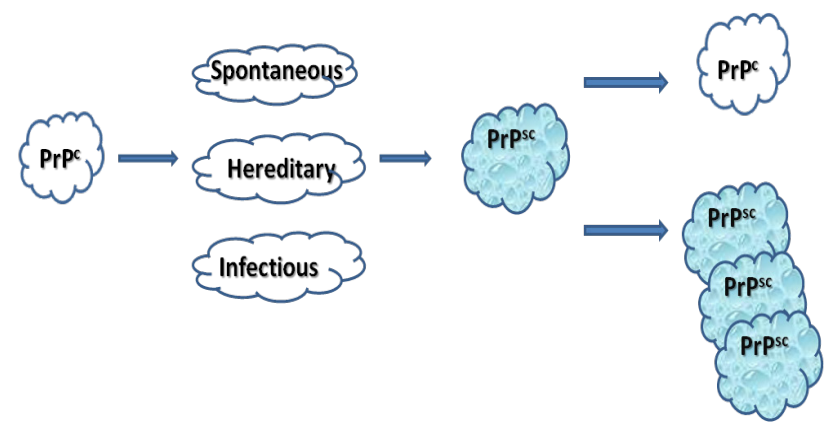

Fig. 2 Schematic illustration of PrPc conversion mechanism

agglomeration of PrPsc and this can be detected by optical trapping and fluorescent imaging. These forces govern the integrity of amyloid fibres. The self templating properties of amyloidogenic proteins are used to tether prion fibrils to be manipulated in optical trap. At normal pulling forces, the fibrils are impervious to disruption. At much higher forces, $250 \mathrm{pN}$, discontinuities occurred in force extension. Experiments with selective amyloid disrupting agents and mutations demonstrated that such discontinuities were caused by the unfolding of individual subdomains. Prion fibrils are remarkably resistant to mechanical forces. This serves as an evidence for tracing infectious particles [12].

\section{Detection based on protein confirmations}

Prions do have a peculiar folding pattern in their secondary structure formations. Comparison of normal and infected proteins by FTIR provides clear evidence about their presence, leading to their ultrasensitive detections in pools of proteins. Normal PrPc structure has been derived from FTIR peaks which contain $40 \%$ $\alpha$-helical content with little or no $\beta$-sheet. The PrPsc types contain $50 \% \beta$-sheets. Comparison of the secondary structures by FTIR of the normal and PrPsc provided additional evidence about their structural variations. Direct determination of the secondary structure content of this portion presented solutions to the methodology of generation of infectious particles [13].

When protein is heated, it unfolds and loses its native conformation. Small- molecule binding can often stabilize the native conformation of a protein, leading to a higher unfolding temperature. This shift in unfolding temperature can be detected using sensitive dyes. A CCD camera was used for proper detection of the output [14].

Bioconformatics emerges as a novel field using sequence specific detection of prion conformations. The technology uses small peptides that mimic the misfolding to detect it. When peptides associate with a misfold it changes shape itself. The peptide labeled on each end with a fluorophore that emits a signal as the shape change occurs, giving us a quantitative data on the $\beta$ sheets present. The reaction is highly sensitive and it exists as an ensemble. Antibodies or Proteinase $\mathrm{K}$ are not required for the reaction.

\section{Interaction based methods}


NMR and X-ray Crystallography helps to study the interactions between small molecules and protein targets. The interaction between small molecules and protein is monitored by the chemical shift of the compound along with saturation transfer difference and simple relaxation measurement [15].

Mass spectrometry has been an accepted method of detection. A separation step has to be involved before MS to remove unbound compounds. Size exclusion, affinity based or ultra filtration can be used for the same. Target prions are immobilized onto solid support with an affinity tag. Compounds are bound to target protein and unbound compounds are washed away. Bound compounds are eluted [16].

\section{Nucleic acid based methods}

DNA encoding is possible methodology for detecting very low concentrations of prions as well as proteins. The detection strategy employs immune-PCR. There are four different approaches for tagging of small molecules. In the first approach, nucleotides are conjugated to small molecule building blocks and are then assembled to longer DNA oligonucleotides by DNA polymerase. Then, synthesis of building blocks to complex chemicals is done. In the second process, DNA tags are conjugated to small molecule building blocks which are ligated enzymatically and then similar reactions as the first are carried out. The third method conjugates a small molecule to a single DNA strand and then attaches a second small molecule to the complementary strand. The fourth method involves a piece of double stranded DNA named the headpiece is bound with a covalently closed end linker to which a small molecule scaffold core is attached. Following addition of a small molecule building block to the scaffold core, another DNA tag which encodes the identity of the chemical building block is ligated to the headpiece. This process is repeated for several cycles to produce vary large combinatorial libraries each containing unique DNA tags [17].

Aptamers are single stranded DNA or RNA oligonucleotides with a size range of 20-80 bases that can be folded to well defined 3D structures such as proteins and phospholipids with high affinity and sensitivity. They are capable of penetrating tissues better than antibodies because of their smaller size. Aptamer binding sites include grooves and clefts that might be present on the target molecules similar to the structures that act as binding sites for small -molecule drugs [30].

\section{Immuno based methods}

Immunoblotting techniques including Western blotting, dot blotting and slot blot analysis are of the most often used methods of prion detection. With these techniques, scientists can detect the proteins of interest using specific antibodies with very high accuracy. Proteins thus separated based on molecular weight are transferred from SDS PAGE to a nitrocellulose membrane. Then the prion protein is detected using antibodies similar to immunohistochemistry using primary and secondary antibodies along with an antigen complex. Staining, chemiluminescence, autoradiography and fluorography can be used for observation purpose [19].

Monoclonal antibodies are raised to copper refolded $\operatorname{PrP}$ to analyze the normal and diseased prions. The antiPrP monoclonal antibodies were reactive by western blot and ELISA with recombinant murine prions. PrPc refolded in the presence or absence of either copper or manganese. The monoclonal antibodies were shown to react with the unglycosylated and monoglycosylated forms of PrPsc in tissue samples. The majority of these monoclonal antibodies recognized the $\mathrm{C}$-terminal portion of PrP. These may therefore be used to examine whether alterations occur in expression or conformation of Cell surface PrP. They also lend themselves to a diagnostic evaluation concerned with modulation of epitopes within $\operatorname{PrP}[21]$.

Immunohistochemistry is the light microscopic visualization of an antigen/ antibody reactions in tissues. Polyclonal and monoclonal antibodies have been used to stain formalin- fixed or paraformaldehyde or paraffin imbedded sections tissues. PrP specific antisera raised against purified preparations has been shown to be effective in identification of bound antibodies. These stained regions show birefringence under polarized light [23].

ImmunoPCR has been commonly used for the detection of many of the prion diseases and can be considered as a potential method for the detection of prions at very low concentrations. This technique binds an antibody detection step similar to an ELISA with nucleic acid amplification by a real time PCR procedure. The results were analyzed by running the PCR product on a $1.2 \%$ agarose gel electrophoresis and visualized by ethidium bromide staining and observing the intensity and band size [18].

RNA Polymerase Immuno Detection (RAPID) is a combinatorial method developed from the available Immuno Polymerase Chain Reaction (IPCR) method which has been optimized for maximum sensitivity through a number of modifications. It uses an RNA polymerase to produce RNA transcripts at isothermal temperatures and a magnetic bead solid support. The sensitivity has been reported to be about 100 attograms $/ \mathrm{ml}$ of recombinant prion protein. This sensitivity is believed to be required for Pre-symptomatic detection of $\operatorname{PrP}$ in blood. Fluorescent transcripts which are the outcomes of the method are verified by gel electrophoresis and real time PCR data. The ability to detect fluorescence directly in the reaction tube allows the detection without any sophisticated instrument [25].

Selective absorption of prion proteins to an affinity ligand optimized for prion capture and attachment to synthetic resin particles has been widely used for applications for prion related studies (20). These 
absorptions work on the basic principle of affinity based chromatographic procedures which can trap selective prion molecules with an altered conformation with strong binding to ligand molecules.

Targeted protein and nucleic acid biomarkers are helpful in detecting diseases and confirming diagnosis very early on. The availability of this highly sensitive, quantitative, automated, cost-effective and easy to use methodology to identify proteins in minute concentrations prove to be better than conventional ELISA based assays as it is 1,000-10,000 fold more sensitive with a detection limit in attomolar ranges [22]. Erythriod differentiation Related Factor (EDRF) serves as one of the important factors for biomarker based identification.

\section{Single molecule based methods}

The advantage of single molecule based methodology is that it can reveal individual static and dynamic behaviours in seemingly identical but in fact, heterogeneous biomolecules. Identification of conformational differences in prion individual molecules thus becomes possible. This type of analysis is presently dominated by two different kinds of approaches- Atomic force microscopy and optical methods. The optical methods include FRAP- Fluorescence Recovery After Photobleaching and FRET- Fluorescence resonance Energy Transfer with single molecule resolution. Fluorescence Correlation Spectroscopy is a novel field for single molecule detection covering a wide spectrum of structural and functional variations in prions. A measured volume even smaller than 10-5 litres is achieved by simply focusing a laser beam down to the resultion limit by an objective with high numerical aperture. Fluorescence is excited within the illuminated region and molecules in this focus contribute the measured signal [26].

Laser induced Fluorescent spectroscopic detection of $\operatorname{PrP}$ with capillary electrophoresis is possible. A competitive assay for $\mathrm{PrP}$ with fluorescent tagged peptides from prions and the specific antibody is involved. Very small levels of PrP in tissues as well as blood ie., low levels up to 10 picograms can be detected [24].

Field Flow Fractionation is an analytical study based on the aggregating potential of prion units. Asymmetric Frit Inflow Field Flow Fractionation (FIFFF) and Thermal Field Flow Fractionation (ThFFF) are recently applied to correlate the size of prion particles with infectivity. Protease resistant PrP protein aggregates were fractioned and the molar mass and hydrodynamic radius was determined using Quasi Elastic light scattering (QELS) [27].

The in vitro replication of protein conformation is called Protein Misfolding Cyclic amplification (PMCA). To estimate the rate of amplification, a densitometric analysis of immunoblots from different samples is done. This system has been used to study the molecular mechanism of PrP conversion, the sequence specificity of PrPsc formation and to identify and evaluate inhibitors of PrP transformation. Early detection of PrPsc from non brain sources is possible with highly sensitive methods. It also favours for the detection of low quantities by means of amplifying undetectable amounts of the protein to a detectable level [28].

\section{Biosensor based methods}

The trends toward multianalyte and miniaturized sensors have produced microarray-type technologies where the active elements features are on the order of microns in size, allowing for thousands of target molecules (e.g., DNA sequences, RNA sequences, proteins) to be displayed simultaneously on chips only a few square centimeters in area. The identification of materials is obtained by binding patterns that are visualized by tags of fluorescent molecules. Fluorescence pattern on an array chip for identifying DNA fragments is followed for accurate detection.

Surface nanotechnology finds application in biomolecular profiling through Reverse Phase Protein Microarrays (RPMA). These enable high throughput screening of post translational modifications of signaling proteins within diseased cells. Silicon with low intrinsic autofluorescence has been explored as a potential microarray surface. Using the combinatorial method of surface roughening and surface coating, the silicon surfaces were shown to transform native silicon into a protein binding substrate comparable to nitrocellulose serving as the most suitable substrate for RPMA [29].

Microfluidic technology uses the inherent properties of liquid and gases at the microscale, combined with semiconductor. Analysis of stable as well as conventional proteins through SDS-PAGE and colorimetry utilizes the properties of microfluidics. It also allows the active control of fluids in microfabricated channel without any interference. The commercial form 'Bioanalyser' integrates multiple experimental procedures such as sample separation, staining, detection and data analysis. Protein identification by digestion is done by electrospray and ionization mass spectrometry. The advantages include usage of nanogram levels of sample and rapid identification in minutes along with separation schemes from complex mixtures or lysates.

Different types of biosensors employing varied functional principles can find effective detection for pico or attomolar concentrations of prions. A nanobiosensor is a probe that integrates a biological component, such as a whole bacterium, enzymes or antibodies with an electronic component to yield a measurable signal. The nanoprobes are fabricated with distal ends having sizes of 30-50 nms. The nanoscale sensors allow changes in protein conformations at single molecule level. There are different types of sensors. Fibre optic nanoprobes are covalently bound with antibodies which are selective targets to analyte molecules. The fluorescence emission from analyte molecules is connected to a microscope. Changes caused by the conformations leading to altered 
information helps in measuring detectable signals. Cantilever based nanomechanical detection helps the detection of biomolecules by measuring nanomechanical forces and it offers an exciting opportunity for the development of sensitive, miniaturized sensors. Micron sized silicon cantilever beams undergo bending due to surface stresses created by molecular adsorption. The resonant frequency also varies due to mass loading. These variations can be measured by optical beam deflection, piezoresistivity, piezoelectricity and capacitance [31].

A novel technology employing surface interactions of B-lymphocytes expressing antibodies with prions is a promising route for detection based on biosensor effect. The B-lymphocytes are genetically engineered to express an antibody of interest on the cell surface and calcium sensitive protein in the cell's cytosol. The interaction of antigen with the membrane bound antibody cause the engineered biosensors to emit light, which is detectable by small, portable Luminometer. The steps include 1 . Obtaining sequences of light and heavy chains of variable region of anti- prion monoclonal antibody by RT-PCR. 2. Construction of a two vector antibody expression system. 3. Generation of a stable cell line that expresses the recombinant antibody on its surface and a calcium sensitive bioluminescent protein in the cell's cytosol that responds to prion antibody. A special type of biosensing was developed using an anti-prion monoclonal antibody. Fluorescen iso thio cyanate labeled with prion epitope for detection. Addition of Sodium Dodecyl Sulfate (SDS) at $0.3 \mathrm{mg} \mathrm{mL}^{-1}$ to gelatin samples facilitated detection in gelatin. The lowest detectable concentration of prion in gelatin was $0.5 \mathrm{nmol} \mathrm{L}^{-1}$ [32].

\section{Nanotechnology based methods}

Structured nanomaterials can be used for the detection of prions. Surface Enhanced Raman based biosensing can be used for testing the presence of prion molecules assisted by structured nanomaterials. Complex optical sensing biochemistries are being attached to nanoparticles called PEBBLES (Probes Encapsulated By Biologically Localised Embedding). The technique is used for measuring the concentration of prions. Two different constructs are linked by a peptide substrate and recognition site (in case of normal proteins). But when the peptide substrate is modified in a prion, the conformational changes cause a modification in the binding of the recognition site. This brings in a change in the efficiency of fluorescence resonance energy. Different levels of fluorescence begin to appear.

Dynamic resonance based techniques with mass labeling technique in a sandwich based assay is employed to enhance the frequency shift for the detection of prions. They are collectively called Nanomechanical resonator arrays and secondary Mass labeling. Resonant sensors are sensitive for mass detection, with analytical sensitivities upto femtograms or even less. Large array devices with arrays of low stress silicon nitride resonators are created that has an improved sensitivity. Functionalization of device was done with silanization and gluteraldehyde chemistry. With the use of functionalized nanoparticles, the sensitivity improved further to orders of $2 \mathrm{ng} \mathrm{mL} \mathrm{m}^{-1}$ [33]. The resonators are fabricated from a $200 \mathrm{~nm}$ thick layer of low stress silicon nitride deposited on $1.5 \mu \mathrm{m}$ thick layer of silicon dioxide. Patterning was enabled with optical photolithography and the resonant frequencies were measured. A $405 \mathrm{~nm}$ diode laser was modulated in intensity and used to heat and excite the resonators. Thermal expansion mismatch between silicon nitride and oxide is responsible for sensor actuation. Resonant frequencies were determined by measuring the reflectance variation from laser. An array of resonators was used for evaluating the concentration of prions. The resonators were exposed to PrP and subsequently with secondary antibodies and nanoparticles for mass labelling. For the detection of $\operatorname{PrP}$, the resonant frequency of each device was measured before and after exposing the resonators to PrP.

Nanoparticle immobilization assay has been developed to enable the binding of nanoparticles to specific prion proteins. This paves the way for the selection of misfolded prion proteins from the whole lot of native proteins with PrP forms. Synthesized nanoparticles serve as prion protein carriers after carbodiimide activation in the presence of N-hydroxysuccinimide. FTIR and TEM were used for the confirming the binding properties. The formation of prion protein complexes reveals the 3 dimensional structures and the prion protein kinetics involved [34].

A highly sensitive and molecular size selective method for the detection of proteins using heteroliganded gold is identified with Localised Surface Plasmon Resonance (LSPR). Two different heteroligands with different chain lengths were used in fabricating nanoholes for size dependent separation of a protein. The binding produces distinct shifts in the LSPR peaks, which can be detected by UV visible spectrophotometry. With a lower detection limit of $1.0 \mathrm{ng} / \mathrm{ml}$, the method can be used to detect small concentrations of prions distributed in the protein population [35].

A nanowire covalently linked to a tyrosine kinase could be used for the detection of small molecule inhibitors by monitoring the conductivity. As very small volumes are required for this study, minimal prion proteins would be enough for the analysis. A nanoscale Surface Plasma Resonance chip was coupled with nanoparticles to detect binding interactions and identification of small molecules [36]. Libraries containing upto 24 individual nanowire sensors have been constructed for the purpose of rapid, high throughput, highly multiplexed biomolecular detection [37].

The biobarcode assay is a powerful amplification and detection system for proteins. In case of proteins the detection agent is a monoclonal antibody. The second is a nanoparticle with a recognition agent that can sandwich the target with the microparticle. The nanoparticles 
carries with it hundreds of oligonucleotides referred to as barcodes. Once the two particles have sandwiched the target, a magnetic field can be used to separate the complexed target from sample solution. Protein or prion targets as low as attomolar levels can be detected [38].

\section{Therapeutic measures for prion diseases}

\section{Available drugs for therapy}

Many drugs have been discovered which have the capacity to reisist the binding and proliferation for PrPs in invitro culture conditions. But few of them have been proved to be effective for human administration. Quinacrine, chlorpromazine and some tricyclic derivatives with an aliphatic side chain were described as efficient inhibitors of PrPsc formation. These drugs have promising activities in curing malaria and psychosis $[39,40]$. Amphotericin B and some analogs delayed the appearance of spongiosis, astrogliosis and PrPsc accumulations in brain [41, 42]. Pentosan polysulphonate, which is prevalent in the treatment of interstitial cystitis as an anticoagulant, when administered intracerebrally, prolonged the incubation time [43]. Polyamines Polypropyleneimine (PPI) has been reported to reduce the concentration of PrPsc appearing in the tissue [44]. Certain other drugs used for the treatment and reduction of appearance of PrPsc are, Cyclic tetrapyrrols [45], Anthracyclins [46], Aptamers [47], Dextran Sulphate [48], Suramin [49], congo red [50], Quinolines [51], Bisacridine derivatives [52], Cyclic tetrapyrroles [53], Filipin [54], $\beta$-sheet breaker [55] etc. Cholesterol inhibitors such as lovastatin and sequalestin, when added to cells reduced the propagation of PrPscs. The disease symptoms were delayed with simvastatin [56]. Peptide aptamers (bacterial thioredoxin) are combinatorial peptides of 16-20 residues in length presented by a constant protein scaffold. They are conformationally constrained and bind to the protein target with high binding affinity. When recombinant aptamers were added to culture media of infected cells with PrPsc, the propagation of PrPsc was inhibited and came down to undetectable levels. Three such aptamers have been identified which inhibited PrPsc conversion in infected cells based upon the peptide sequence and sorting signal [57]. Autoimmunization has been considered as one of the remedies for Prion infection. Antibodies raised as monoclonal or polyclonal antibodies were tested for inhibition of PrPsc conversion. Besides inhibiting the conversion and interactions, endocytosis and degradation are enhanced. A novel antigen, resembling a putative folding intermediate, consisting of two covalently linked murine PrP molecules without $\mathrm{N}$ and $\mathrm{C}$ terminal signal peptides was used for immunization [58]. RNA aptamers are small combinatorial RNA molecules selected from genomic libraries. As targets for selecting anti- PrP RNA aptamers, a peptide comprising human PrP has been chosen in the region of 90-129 due to its importance in conversion process. The nuclease resistant complex binds with high affinity to the recombinants of PrPs of different species. The formation of high molecular mass aggregates is impeded, so that the misfolded PrP becomes more susceptible to Protein Kinase digestion [59]. Imatinib effectively accelerated the degradation of PrPsc and reduced its half life. Overexpression of c-abl the transdominant negative mutant allele affected the accumulation of PrPsc. Cellular autophagy was found to be induced by imatinib [60]. Leukotrap affinity Prion reduction filter is a filter that was developed to overcome the current limitations of leukocyte reduction filters. It removes leukocytes and all types of prions- cell associated and non cell associated in a single step based on a surface modification technology that removes all types of prions aggregated, denatured or normal. The packed red blood cells for transfusion are subjected to both invitro and invivo studies with the filter. The concentration of the prions tend to reduce below detectable values by western blot ie., reduction occurs by $99.9 \%$. Besides acting as a safe methodology for transfusion, it can also serve as an important tool to detect and eliminate the prion population in diverse proteins in blood [61].

\section{Drug delivery systems}

Nanoparticle based drug delivery can be promising to overcome the hindrance of Blood Brain Barrier (BBB). Crossing the blood brain barrier by therapeutic molecules is a deadlock hence the circulatory network is separated from brain by a highly impermeable endothelial cells with tight junctions, supported by active efflux transport systems. It prevents the transport of water soluble molecules from blood circulation and allows highly essential molecules for the functional activity of brain. These phenomena remain as one of the important barriers in designing and sending the therapeutic molecules to treat as well as reduce the concentration of prions [62]. The use of nanoparticles to deliver drugs to brain by infiltrating Blood Brain Barrier (BBB) provides a significant strategy to break this impasse. The system also reduces drug leaching in the brain and peripheral toxicity. PEGylated polymeric nanoparticles as drug carriers have proven to be efficient for treating prion diseases. Adsorption of drugs to polysorbate 80 coated nanoparticles increases the transport of a number of substances across BBB eg., polar hexapeptide dalargin, tubocurarine, loperamide and doxorubicin. Polymeric nanoparticles are promising carriers for Central Nervous System drug delivery due to their potential in encapsulation and protection form

\section{References}

1. Prusiner SB, Scott MR, DeArmond SJ, and Cohen FE. Prion protein biology. Cell. 1998; 93:337-348.http://dx.doi. org/10.1016/S0092-8674(00)81163-0

2. Prusiner SB. Novel proteinaceous infectious particles cause scapie. Science 1982; 216:136-144.http://dx.doi.org/10.1126/ science. 6801762

3. Safar J. Eight prion strains have PrPsc molecules with different conformations. Nature. Med. 1998; 4:1157-1165.http://dx.doi. org/10.1038/2654

4. Moreno CR, Lantier I, Sarradin P, and Elsen J M. . Detection of new quantitative trait loci for susceptibility to transmissible spongiform encephalopathies in mice. Genetics. 2003; 165:20852091.

5. Prusiner SB. Genetic and Infectious prion diseases. Arch. Neurol. 
1993; 50(11): 1129-53.http://dx.doi.org/10.1001/ archneur.1993.00540110011002

6. Rudi Glockshuber, Simone Hornemann, Martin Billeter1, Roland Riek, Gerhard Wider, Kurt Wuëthrich. Prion protein structural features indicate possible relations to signal peptidases. FEBS Letters 1998; 426:291-296http://dx.doi.org/10.1016/S00145793(98)00372-X

7. Oesch B, Westaway D, Walchli M, McKinley MP, Kent SB, Aebersold R, Barry RA, Tempst P, Teplow DB, Hood LE. A cellular gene encodes scrapie PrP 27-30 protein. Cell 1985; 40: 735-746. http://dx.doi.org/10.1016/0092-8674(85)90333-2

8. Caughey B, Kocisko DA, Raymond GJ, Lansbury PT Jr. Aggregates of scrapie-associated prion protein induce the cell-free conversion of protease-sensitive prion protein to the protease- resistant state. Chem. Biol.1995; 2:807-817.http://dx.doi.org/10.1016/10745521(95)90087-X

9. Prusiner SB. Molecular biology of prion diseases. Science. 1991; 252:1515-1522.http://dx.doi.org/10.1126/science.1675487

10.Pan KM, Baldwin M, Nguyen J, Gasset M, Serban A, Groth D, Mehlhorn I, Huang Z, Fletterick RJ, Cohen FE. Coversion of alpha -helices into beta sheets features in the formation of the scrapie prion proteins. 1993; 90(23):10962-6.

11. Thurmond RL, Wadsworth SA, Schafer PH, Zivin RA, Siekierka JJ. Kinetics of small molecule inhibitor binding to p38 kinase. Eur. $J$ Biochem. 2001; 268:5747-5754.http://dx.doi.org/10.1046/j.00142956.2001.02512.x

12. Cervenakova L, Brown P. 2004. Advances in screening test development for transmissible spongiform encephalopathies. Expert Rev. Anti Infect Ther. 2: 873-880http://dx.doi.org/10.1586/14789072. 2.6.873

13. Thuring CM, Erkens JH, Jacobs JG, Bossers A, Van Keulen LJ, Garssen GJ, Van Zijderveld FG, Ryder SJ, Groschup MH, Sweeny T, and Langeveld JP. 2004. Discrimination between scrapie and bovine spongiform encephalopathy in sheep by molecular size, immunoreactivity, and glycoprofile of prion protein. J Clin Microbiol 2004; 42: 972-80.http://dx.doi.org/10.1128/JCM.42.3.972-980.2004

14. Pantoliano MW, Petrella EC, Kwasnoski JD, Lobanov VS, Myslik J, Graf E. High density miniaturized thermal shift assays as a general strategy for drug discovery. J. Biomol. Screen. 2001; (6): 429-440. http://dx.doi.org/10.1177/108705710100600609

15. Hajduk PJ, Betz SF, Mack J, Ruan X, Towne DL, Lerner CG. A strategy for high throughput assay development using leads derived from nuclear magnetic resonance based screening. J. Biomol. Screen. 2002; 7: 429-432.http://dx.doi.org/10.1177/108705702237674

16. Annis DA, Athanasopoulos J, Curran PJ, Felsch JS, Kalghatgi K, Lee WH, An affinity selection mass spectrometry method for the identification of small molecule ligands from self- encoded combinatorial libraries. Int. J. Mass. Spec. 2004; 238: 77-83.

17. Melkko S, Zhang Y, Dumelin CE, Scheuermann J, Neri D. Isolation of high affinity trypsin inhibitors from a DNA encoded chemical library. Angew Chem. Int. Ed. Eng. 2007; 46: 4671-4674. http://dx.doi.org/10.1002/anie.200700654

18. Jijun Dong, Carlos E Castro, Mary C Boyce, Matthew J Lang \& Susan Lindquist. Optical trapping with high forces reveals unexpected behaviors of prion fibrils. Nature Structural \& Molecular biology 2010; 17(12):1423-1430http://dx.doi.org/10.1038/ nsmb. 1954

19. Riek R, Hornemann S, Wider G, Billeter M, Glockshuber $\mathrm{R}$ and Wuthrich K NMR structure of the mouse prion protein domain PrP (121-231). Nature 1996; 382:180-182.http:// dx.doi.org/10.1038/382180a0

20. Hammond D, Lathrop J, Cervenakova L, Carbonell R (inventors): Prion protein ligands and methods of use. US patent WO 2004/ 050851A2; 3: 2003

21. Alana M. Thackray, Jean-Yves Madec., Edmond wong, Robert Morgan-Warren, David R. Brown, Thierry Baron and Raymond Bujdoso. Detection of bovine spongiform encephalopathy, ovine scrapie prion-related protein (PrPSc) and normal PrPc by monoclonal antibodies raised to copper-refolded prion protein Biochem. J. 2003; 370:81-90

22. Lambert MP, Barlow AK, Chromy, BA. Diffusible, nonfibrillar ligands derived from $\mathrm{Ab} 1->42$ are potent central nervous system neurotoxins. Proc Natl Acad Sci. 1998; 95: 6448-53.

\section{http://dx.doi.org/10.1073/pnas.95.11.6448}

23. Bendheim PE, Barry RA, DeArmond SJ, Stites DP \& Prusiner SB. Antibodies to a Scrapie Prion Protein. Nature. 1984; 310:418-421.

24. Schmerr M J, Jenny A. A diagnostic test for scrapie-infected sheep using a capillary electrophoresis immunoassay with fluorescentlabeled peptides. Electrophoresis. 1998;19:409-414 http://dx.doi.org/10.1002/elps.1150190308

25. Crameri G, Wang LF, Morrissy C, White J, Eaton BT. A rapid immune plaque assay for the detection of Hendra and Nipah viruses and anti-virus antibodies. J. Virol. Methods. 2002; 99(1-2):41-51. http://dx.doi.org/10.1016/S0166-0934(01)00377-9

26. Elson El, Magde D. Fluorescence correlation spectroscopy. I. Conceptual basis and theory. Biopolymers. 1997. 4; 13:1-27.

27. S. Kim Ratanathanawongs, Williams Dean Lee Field-flow fractionation of proteins, polysaccharides, synthetic polymers, and supramolecular assemblies. J. Sep. Sci. 2006; 29: 1720 - 1732 http://dx.doi.org/10.1002/jssc.200600151

28. Gabriela P Saborio, Bruno Permanne \& Claudio Soto Sensitive detection of pathological prion protein by cyclic amplification of protein misfolding. Nature. 2001; 411: 810-813.http://dx.doi. org/10.1038/35081095

29. Geho D, Lahar N, Gurnani P, Huebschman M, Herrmann P, Espina V, Shi A, Wulfkuhle J, Garner H, Petricoin E. Pegylated, streptavidin-conjugated quantum dots are effective detection elements for reverse-phase protein microarrays. Bioconjugate Chemistry. 2005; 16:559-566http://dx.doi.org/10.1021/bc0497113

30. Wang KY. et al. A DNA aptamer which binds to and inhibits thrombin exhibits a new structural motif for DNA. Biochemistry. 1993; 32: 1899-1904http://dx.doi.org/10.1021/bi00059a003

31. Ziegler C. Cantilever-based biosensors. Anal Bioanal Chem. 2004; 379:946-959.http://dx.doi.org/10.1007/s00216-004-2694-y

32. Anand A, R Moreira J, Henry M, Chowdhury G, Cote and T. A biosensing strategy for the detection of prions in foods. Good. 2005; 38(8): 849-858

33. Madhukar Varshney, Philip S Waggoner, Christine P Tan, Keith Aubin, Richard A. Montagna, and Harold G Craighead. Prion Protein Detection Using Nanomechanical Resonator Arrays and Secondary Mass Labeling. Anal. Chem. 2008; 80: 2141-2148 http://dx.doi.org/10.1021/ac702153p

34. Gilles K Kouassi and Joseph Irudayaraj. A nanoparticlebased immobilization assay for prion-kinetics study. Journal of Nanobiotechnology. 2000; 6: 4-8

35. Surin Hong, Suseung Lee and Jongheop Yi. Sensitive and molecular size-selective detection of proteins using a chip-based and heteroliganded gold nanoisland by localized surface plasmon resonance spectroscopy. Nanoscale Research Letters. 2011; 6:336 http://dx.doi.org/10.1186/1556-276X-6-336

36. Wang WU, Chen C, Lin KH, Fang Y, Lieber CM. Label free detection of small molecule protein interactions by using nanowire nanosensors. Proc. Natl. Acad. Sci. USA. 2005; 102: 3208-3212. http://dx.doi.org/10.1073/pnas.0406368102

37. Beckman R, Johnston-Halperin E, Luo Y, Green JE, Heath JR. Bridging dimensions: demultiplexing ultrahigh-density nanowire circuits. Science. 2005; 310:465-468.http://dx.doi.org/10.1126/ science. 1114757

38. Nam J-M, Park S-J, Mirkin CA. Bio-barcodes based on oligonucleotide-modified nanoparticles. J Am Chem Soc. 2002; 124:3820-3821.http://dx.doi.org/10.1021/ja0178766

39. Doh-Ura K, Iwaki T, Caughey B. Lysosomotropic agents and cysteine protease inhibitors inhibit scrapie associated prion protein accumulation. J. Virol. 2000; 74:4894-97http://dx.doi.org/10.1128/ JVI.74.10.4894-4897.2000

40. Korth C, May BC, Cohen FE, Prusiner SB. Acridine and phenothiazine derivatives as pharmacotherapeutics for prion disease. Proc. Natl. Acad. Sci. USA 2001; 98:9836-41 http://dx.doi.org/10.1073/pnas.161274798

41. Adjou KT, Privat N, Demart S, et al. MS-8209, an amphotericin B analogue, delays the appearance of spongiosis, astrogliosis and PrPres accumulation in the brain of scrapie-infected hamsters. $J$. Comp. Pathol. 2000; 122:3-8http://dx.doi.org/10.1053/ jсpa.1999.0338

42. Pocchiari M, Schmittinger S, Masullo C.Amphotericin B delays the incubation period of scrapie in intracerebrally inoculated hamsters. $J$. 
Gen. Virol. 1987; 68:219-23http://dx.doi.org/10.1099/0022-131768-1-219

43. Doh-Ura K, Ishikawa K, Murakami- Kubo I, et al. Treatment of transmissible spongiform encephalopathy by intraventricular drug infusion in animal models. J. Virol. 2004; 78:4999-5006 http://dx.doi.org/10.1128/JVI.78.10.4999-5006.2004

44. Supattapone S, Nguyen HO, Cohen FE, et al. Elimination of prions by branched polyamines and implications for therapeutics. Proc. Natl. Acad. Sci.USA 1999; 96:14529-34http://dx.doi.org/10.1073/ pnas.96.25.14529

45. Priola SA, Raines A, Caughey WS. Porphyrin and phthalocyanine antiscrapie compounds. Science. 2000; 287:1503-6http://dx.doi. org/10.1126/science.287.5457.1503

46. Tagliavini F, McArthur RA, Canciani B, et al. Effectiveness of anthracycline against experimental prion disease in Syrian hamsters. Science. 1997; 276:1119-22http://dx.doi.org/10.1126/ science. 276.5315 .1119

47. Proske D, Gilch S, Wopfner F, et al. Prion-protein-specific aptamer reduces PrPSc formation. Chembiochemistry. 2002: 3:717-25 http://dx.doi.org/10.1002/1439-7633(20020802)3:8<717::AID$\mathrm{CBIC} 717>3.0 . \mathrm{CO} ; 2-\mathrm{C}$

48. Adjou KT, Simoneau S, Sales N, et al. A novel generation of heparan sulfate mimetics for the treatment of prion diseases. J. Gen. Virol. 2003; 84:2595-603http://dx.doi.org/10.1099/vir.0.19073-0

49. Gilch S, Winklhofer KF, Groschup MH, et al. Intracellular rerouting of prion protein prevents propagation of $\operatorname{PrP}(\mathrm{Sc})$ and delays onset of prion disease. EMBO J. 2001; 20:3957-66http://dx.doi. org/10.1093/emboj/20.15.3957

50. Caughey B, Race RE. Potent inhibition of scrapie-associated PrP accumulation by Congo red. J. Neurochem. 1992; 59:768-71 http://dx.doi.org/10.1111/j.1471-4159.1992.tb09437.x

51. Murakami- Kubo I, Doh-Ura K, Ishikawa K, et al. Quinoline derivatives are therapeutic candidates for transmissible spongiform encephalopathies. J. Virol. 2004; 78:1281-88http://dx.doi. org/10.1128/JVI.78.3.1281-1288.2004

52. May BC, Fafarman AT, Hong SB, et al. Potent inhibition of scrapie prion replication in cultured cells by bisacridines. Proc. Natl. Acad Sci. USA 2003; 100:3416-21http://dx.doi.org/10.1073/ pnas. 2627988100

53. Priola SA, Raines A, Caughey WS. Porphyrin and phthalocyanine antiscrapie compounds. Science. 2000; 287:1503-6http://dx.doi. org/10.1126/science.287.5457.1503

54. Marella M, Lehmann S, Grassi J, et al. Filipin prevents pathological prion protein accumulation by reducing endocytosis and inducing cellular PrP release. J. Biol. Chem. 2002; 277:25457-64 http://dx.doi.org/10.1074/jbc.M203248200
55. Soto C, Kascsak RJ, Saborio GP, et al. Reversion of prion protein conformational changes by synthetic betasheet breaker peptides. Lancet 2000; 355:192- 97http://dx.doi.org/10.1016/S01406736(99)11419-3

56. Bate C, Salmona M, Diomede L, Williams A. Squalestatin cures prion infected neurons and protects against prion neurotoxicity. $J$ Biol. Chem. 2004; 279 (15):14983-90http://dx.doi.org/10.1074/jbc. M313061200

57. Baines IC, Colas P. Peptide aptamers as guides for small molecule drug discovery. Drug. Discov Today. 2006; 11(7-8): 334-41 http://dx.doi.org/10.1016/j.drudis.2006.02.007

58. Beringue V, Vilette D, Mallinson G, Archer F, Kaisar M, Tayebi M, Jackson GS, Clarke AR, Laude H, Collinge J, Hawke S. PrPsc binding inhibitors of prion replication in cell lines. $J$ Biol Chem. 2004; 279(38):39671-6.http://dx.doi.org/10.1074/jbc.M402270200

59. Famulok M, Mayer GAptamers as tools in molecular biology and immunology. Curr Top Microbiol Immunol 1999; 243:123-136 http://dx.doi.org/10.1007/978-3-642-60142-2 7

60. Ertmer A, Huber V, Gilch S, Yoshimori T, Erfle V, Duyster J, Elsasser HP, Schätzl HM: The anticancer drug imatinib induces cellular autophagy. Leukemia 2007; 21/5: 936-42.

61. Gregori L, McCombie N, Palmer D, Birch P, Sowemimo-Coker SO, Giulivi A, Rowher RG. Effectiveness of leucoreduction for removal of infectivity of transmissible spongiform encephalopathies from blood. Lancet.2004; 364: 529-531.http://dx.doi.org/10.1016/ S0140-6736(04)16812-8

62. C. Chakraborty B, Sarkar C H, Hsu Z H, Wen CS, Lin P C, Shieh. Future prospects of nanoparticles on brain targeted drug delivery. $J$ Neurooncol. 2009; 93:285-286http://dx.doi.org/10.1007/s11060008-9759-2

63. Giovanni T, Luca C, Barbara R, Flavio F, Maria AV, Polymeric nanoparticles for drug delivery to the central nervous system. Expert Opinion on Drug Delivery. 2008; 5(20): 155-174.

64. Alyautdin RN, Tezikov EB, Ramge P, Kharkevich DA, Begley DJ . Significant entry of tubocurarine into the brain of rats by adsorption to polysorbate 80-coated polybutyl cyano acrylate nanoparticles: an in situ brain perfusion study. J Microencapsul. 1998; 15:67-74. http://dx.doi.org/10.3109/02652049809006836

Copyright:(c) 2012 PK Praseetha, et al. This is an openaccess article distributed under the terms of the Creative Commons Attribution License, which permits unrestricted use, distribution, and reproduction in any medium, provided the original author and source are credited. 